\title{
Simultaneous versus Consecutive Movie Narration: An Attempt at Boosting L2 Oral Communication Skills
}

\author{
Sepideh Tahami ${ }^{1}$, Gholam Reza Parvizi ${ }^{2}$ \\ ${ }^{1}$ Islamic Azad University, North Tehran Branch, TEFL Department, Tehran, Iran \\ ${ }^{2}$ Alborz University, TEFL Department, Qazvin, Iran \\ Correspondence: Sepideh Tahami. E-mail: Sepidar.tahami@gmail.com
}

Received: May 4, 2019

Accepted: May 27, 2019 Online Published: June 5, 2019

doi:10.5430/elr.v8n2p31

URL: https://doi.org/10.5430/elr.v8n2p31

\begin{abstract}
Fluency in one of the most significant components of oral communication, and in the communication era, when it is essential for almost everyone to master speaking skills in foreign languages, especially English, this component needs to be put in the spotlight. Diverse steps have been taken in the world of SLA to promote learners' fluency in L2, yet there is still much to do in this arena. The present study aims at probing the effectiveness of simultaneous movie narrations as a new fluency-booster strategy. To this end, 66 students of IELTS speaking preparation classes in an institute in Tehran, Iran were selected and put into 2 groups of 33 (each group distributed in 3 classes). The homogeneity of the sample was checked by a mock IETLS test obtained from Cambridge IELTS 10 (Cambridge Local Examinations syndicate ( 2015) and through a MANOVA. The treatments contained 24 hours of training and practice on IELTS speaking strategies, offered to them in 16 sessions of 90 minutes. The first half of each session was allocated to teaching and practice on the institute's main course book - Focusing on IELTS - Listening and Speaking Skills (Thurlow \& O'Sullivan, 2011). In the second 45 minutes, learners of both groups were exposed to the same 10-minute movie extracts, and practiced their narration and speaking skills in pair-group activities. Learners of the consecutive narration group narrated the movie plot and actions with delay (consecutively) whereas those of the simultaneous narration group narrated them simultaneously as the movie was being played. The results of the statistical analysis of the posttest highlighted that simultaneous narration group learners outperformed those of the consecutive narration group in terms of oral communication skills. The findings of this study have pedagogical implications for English teachers, teacher trainers, exam preparation teachers and simultaneous interpreters' trainer.
\end{abstract}

Keywords: Consecutive Movie Narration, Oral Communication, Simultaneous Movie Narration

\section{Introduction}

Generally speaking, the ability of functioning in a language is often defined by one's ability to speak that language (Nunan, 1999). In other words, the most important objective of teaching any foreign/second language should be enabling the learners to use that language for making fluent, accurate and effective communication (Davies \& Pearse, 2000). This perspective, which was initiated in the early 1980s and has ever since been well established, and massively and extensively influenced all aspects of L2 teaching field (methodology, material development, assessment, etc.) (Richards, 2006), has strikingly promoted the popularity of communicative-based teaching and driven the majority of language learners to demand improvement in speaking as their main want from L2 teaching systems.

In line with this oral communication-oriented perspective and demand, fluency has turned into the most popular aspect of L2 speaking (Cohen, 1998), communication strategies have walked up the ladder of public interest (Macaro, 2001); and books, learning and teaching strategies, and instructional materials that aim at enhancing learners' speaking proficiency have flooded into language teaching market in the course of the past 20 years (Bailey, 2005). Even when not used for mere communication purposes, speaking is the central part of the language, and provides the medium of instruction and learning for other language skills and components (Johnson \& Johnson, 1998). Hence, adequate speaking skill is essential in communicative classrooms of today, where the dominant classroom language is $\mathrm{L} 2$.

Bailey and savage (1994) proposed that speaking is the most demanding skill as well as the most complicated one 
when it comes to learning a second/foreign language. This is mainly because the development of speaking involves the development of a large number and a wide variety of other language and cognitive skills (Gardner \& Pollard, 1998). Nunan (1998) proposed that comprehensible articulation of sounds, acquiring sufficient number and range of lexicon and learning syntax are the language components that have to be developed prior to the development of speaking. Richards, Webber, and Platt (1985) proposed the development of vocabulary, grammar, thinking strategically and elaborately, speech acts and communication skills such as starting, maintaining and finishing a conversation as the prerequisites to the fostering of speaking skills. Bygate (1987) also made a distinction between the knowledge which is needed to enhance speaking (e.g. vocabulary, functions, grammatical structures, cultural and social awareness) and the skill which is needed for that (thinking, brainstorming, developing ideas, and conversation handling strategies). Even when it comes to skills in this context, Brown and Yule (1983) make a distinction between interactional functions of speaking (used in establishing social connections) and transactional functions (used for give and take of information).

Given this complicated and intermingled nature of speaking, which make it a long-term process and an extremely difficult skill to master, various strategies, methods and activities have been devised and investigated by L2 teaching experts to foster oral communication skills in L2 learners. Krashen (1982) stated that motivation, self-confidence and anxiety are the main three affective factors in language learning and promoting the first two and reducing the last could be the key to have successful L2 speakers. Tam (1997) proposed that putting L2 learners in diverse situations and giving them frequent speaking tasks is one of the key methods of promoting their speaking, particularly their fluency skills. Songsiri (2007) also emphasizes that learners' being put in real-life situations and practicing functioning in those situations could be an excellent means to promote their speaking skills. Doff (1998), on the other hand, emphasized the role of listening in L2 speaking enhancement and asserted that we must have great listeners to have great speakers.

Bachman\& and Palmer (1996) recommended promoting learners' topical knowledge as a means of boosting speaking skills. Khan (2005) emphasized the role of e-learning and asserted that using virtual simulation devices such as virtual reality is an effective way in placing learners in situations where they could practice their speaking and thrive. In the same phase, Ducate and Lomicka (2009) suggested producing podcasts as another speaking booster activity for students. Baker and Westrup (2003) emphasized the role of positive feedback on learners' oral proficiency and maintained that feedbacks by teachers not only promote the quality of learners' speaking but are also reassuring.

Other than these, a large number and a wide variety of other activities and strategies such as information gap activities, group presentations and projects, interviews, simulations of real-life situations, storytelling, guessing games, jigsaw tasks, picture description, discussion and debates, oral reports, and problem solving activities have been recommended in different textbooks and instructional manuals as strategies that could promote the quality of speaking skills in L2 learners. Nonetheless, given the significance of the speaking skill in L2, and the vital role that speaking plays in the language learning destiny of L2 learners, there is still room in the field of L2 speaking research and the world of language teaching still warmly welcomes new strategies of promoting oral communication. As a study of this such, the present paper intended to introduce two new techniques of developing oral communication skills in learners, and comparing their impact via implementing them: Simultaneous narration, which involves learners' watching a video and narrating the scenes and actions of the video simultaneously as they happen; and consecutive narration, which involves learners' watching a video for a short while and narrating its plot and scenes after that (with delay). Hence, the researchers formulated the following research question:

RQ: Is there a significant difference between the impacts of implementing simultaneous narration and consecutive narration on EFL learners' oral communication skills?

And as well, the researchers formulated the following research hypothesis:

$\boldsymbol{R H}$ : There is not any significant difference between the impacts of implementing simultaneous narration and consecutive narration on EFL learners' oral communication skills.

\section{Methodology}

In this section, the methodology of the study, including the features and the selection method of the participants, the instruments, the material, and the design and the variables will be fully discussed.

\subsection{Participants}

The sample of this study was comprised of 66 English language learners who had registered in preparation courses 
for IELTS speaking skill in an institute in Tehran. As the institute policy dictated, all learners had to take the institute placement test before registration in IELTS preparation classes and stage a performance of at least intermediate proficiency level. So it could be stated that the sample were all speakers of intermediate proficiency level or higher. The learners were both male and female, and their age ranged between 19 and 42 . They had different university degrees in different majors, had different careers, and came from a wide variety of socio-economic backgrounds.

Since students needed to participate actively in class activities in IELTS Speaking classes in order to promote their oral proficiency, the institute policy is to hold these classes with a maximum number of 15 students, so the researchers was unable to put the learners into two groups of 33. Instead, with the aid of the institute director, the learners were distributed into 6 classes. Three classes were held on Saturdays and Wednesdays; one from 4:30 pm to 6:00 $0_{\mathrm{pm}}$ with 11 learners, one from 6:15 $\mathrm{pm}$ to 7:45 $\mathrm{pm}$ with 10 learners and one from 8:00 $\mathrm{pm}$ to 9:30 $\mathrm{pm}$ with 11 learners. All the learners in these three classes were assigned to the consecutive narration group. The other three classes were held on Sundays and Tuesdays; one from 4:30 $\mathrm{pm}$ to 6:00 $\mathrm{pm}_{\text {with }} 9$ learners, one from $6: 15_{\mathrm{pm}}$ to 7:45 $\mathrm{pm}$ with 14 learners and one from 8:00 pm to 9:30 $\mathrm{pm}$ with 10 learners. Learners in these classes were assigned to the simultaneous narration. Hence, learners of the consecutive narration and simultaneous narration groups were 33 each, and they were distributed in six classes, three classes being assigned to each group.

In order to make sure that the inter-group homogeneity existed among the 6 groups of the sample in terms of general English proficiency, the researchers administered a mock version of Academic IELTS test to the sample. The results of the MANOVA test, as it will be discussed in the next section, highlighted that the 6 groups enjoyed an acceptable degree of inter-group homogeneity in proficiency in all the four skills.

Other than the main sample, the researchers used a sample of 40 IELTS preparation class students in order to pilot the psychometrics of the mock IELTS pretest. Besides, a second rater participated in the scoring of the writing and speaking papers of the IETLS test administered in this study. The second rater was a PhD candidate in TEFL, and had been working as a professional full-time English teacher for over 18 years.

\subsection{Instruments}

Four different instruments were utilized in the course of this study. The first applied instrument was a mock version of the IETLS test, which was obtained from the popular IELTS preparation reference Cambridge IELTS 10 (Cambridge Local Examinations syndicate, 2015). This test was in the academic module, and consisted of the four sections of listening, reading, writing and speaking. The test served as the pretest, and its score helped the researchers make sure that the learners in the 6 groups of this study had almost equal degrees of general English proficiency. Since this test was a mock version and not a real test, the researchers administered it to a sample of 40 IELTS preparation class students as the pilot sample, and calculated its internal consistency. Cronbach's Alpha analysis reported the alpha coefficient of 0.814 , which indicated the test was highly reliable.

The other two instruments used in this study were the IELTS writing Task 1 and 2 Band Descriptors (Public Version) and IELTS Speaking Band Descriptors (Public Version), which were utilized by the raters to score the writing and speaking parts of the IELTS test, respectively. These band descriptors encompassed a wide variety of constructs such as task achievement, cohesion, coherence, lexical range, grammatical range, grammatical accuracy, pronunciation, and the like. And finally, the researchers utilized another mock version of the IELTS test, obtained from Cambridge IELTS 10 (Cambridge Local Examinations syndicate, 2015), in the posttest. However, since the main focus of this study was measuring the improvement of learners' speaking skills, the researchers only administered the speaking section of the test to the sample in the posttest. The test was scored by the raters based on IELTS Speaking Band Descriptors (Public Version). Just as the standard procedure of the IELTS speaking section, each learner was required to sit in the oral interview for 11 to 14 minutes, and s/he was asked questions in three parts (personal questions and questions of general Interest, cue card and talk, and cue-card-based discussion).

\subsection{Material and Treatment}

The participants of this study were divided into 6 classes, three of which were assigned to the consecutive narration and the others were assigned to the simultaneous narration group. Learners of all 6 classes received 24 hours of training as part of the IELTS preparation course they were attending, which was offered to them in 16 sessions of 90 minutes. Each class met twice a week, so a weekly amount of 3 hours of teaching was involved. All the 6 classes were taught by one of the researchers, in order to maintain the content validity of the study.

The course book of the treatment was the main course book of the institute - i.e., Focusing on IELTS - Listening and Speaking Skills (Thurlow \& O'Sullivan, 2011). The book contains thorough lessons and strategies to prepare IELTS candidates for the speaking and listening sections of this test. Certainly, since the treatment was offered to the 
learners who had registered for speaking preparation classes, the speaking part of the book was merely covered.

Each class session was divided into two 45 -minute sections. In the first 45 minutes, learners were presented with a variety of techniques and strategies needed to attain a high score in IELTS speaking, and they learners participated in various pair/group tasks in order to practice the material they had just learned. Besides, some words, phrases and collocations - based on the topic of the day - were presented to the learners by the teacher as one of the researchers. In the first section of each session, which was just described, no difference exists between the teaching material and procedures used in any of the 6 classes. Thus, the only difference between the treatments offered to the learners of the simultaneous narration groups and those in the consecutive narration groups lies in the second 45 minutes of the class.

In the second half of each session, learners were engaged in movie-based activities. The teacher cut out sixteen 10-minute extracts from 16 different movies, and played one extract in every session. Learners in the consecutive narration group watched the extracts 2 minutes by two minutes and then worked in pairs and groups to narrate the events of the movie for each other. In the end, they answered some comprehension questions posed by the teacher. Learners of the simultaneous narration group, however, always worked in pairs. They sat in front of the classroom television in two rows, in a way that one row of learners faced the television and watched the movie and the other row sat with their backs to the television and did not see the screen. Each pair sat close to each other and the partner that saw the screen narrated the events of the movie simultaneously as they happened to the partner that did not see the screen. Then, the teacher would pause the movie, and ask some comprehension questions from the students who had not seen the movie, to realize how well their partners had narrated the events.

Since the movie extracts were supposed to provide learners with speaking practice material and not listening material, they must have included a lot of actions and events rather than conversations; hence, the extracts from the parts of the each movie that contained action scenes rather than conversation scenes were cut out. It should also be added that all the comprehension questions the researchers asked the learners of each group were based on the events and actions in the movies not conversations. The researchers selected these movies since panel of experts in this field approved that the movies are interesting to watch by learners of the age and there are certain part of the movies in which dialogues contain non-test conditions reflecting authenticity, interactiveness, incidental learning enhancement, cultural references, and thinking patterns of English-speaking people. Films were selected according to the learners' tastes from a wide range of different genres, plots, and focused topics of the class that were supposed to draw their attention. Besides, consistency of the outcome over the time and practicality of the movies as material have beneficial impacts on the learners. Therefore, test usefulness parameters including interactivesness, construct validity, impact, reliability, practicality, and authenticity are included in test task of the language use. A list of the movies from which the extracts were cut out could be accessed in Table 1.

Table 1. List of the Movies from which Extracts were Made

\begin{tabular}{cc}
\hline Treatment Session & Movie Titles \\
\hline Session 1 & Full Metal Jacket \\
Session 2 & Mission Impossible I \\
Session 3 & Quantum of Solace \\
Session 4 & Terminator II \\
Session 5 & Scent of a Woman \\
Session 6 & 88 Minutes \\
Session 7 & Olympus has Fallen \\
Session 8 & Good Fellas \\
Session 9 & Fight Club \\
Session 10 & Lord of the Rings II \\
Session 11 & Pulp Fiction \\
Session 12 & Silence of the Lambs \\
Session 13 & Eyes Wide Shut \\
Session 14 & The Titanic \\
Session 15 & Mulholland Drive \\
Session 16 & Avatar \\
\hline
\end{tabular}


Hence, learners of both groups were exposed to the same lessons and the same course book for the first 45 minutes of each class session. In the second 45 minutes, as well, they were exposed to the same movie extracts, answered the same questions and worked merely on their narration and speaking skills in pair-group activities. The only difference, however, was that the learners of the consecutive narration group narrated the movie plot and actions with delay (consecutively) whereas those of the simultaneous narration group narrated them simultaneously as the movie was being played.

\subsection{Design}

Since the sample of this study was selected through convenience sampling, and random selection did not take place, the study enjoys a quasi-experimental design. The independent variable of the study is the type of narration that learners apply while watching movies, and the only dependent variable is the development of learners' oral proficiency. Moreover, since the policy of the institute where the study was administered dictates that learners in IELTS preparation classes have to be at least in intermediate proficiency level of general English, general English is a control variable in this study, and considering the institute focused exclusively on adult education and did not register learners below the age 18 , it could be argued that age was another control variable.

\subsection{Statistical Analysis Procedures}

Measures of descriptive statistics (mean and standard deviation) were used for the general description of the data. Furthermore, normality of distribution was also checked. In terms of inferential statistics, Pearson Correlation was utilized to check the inter-rater reliability of the scores in speaking and writing section of the IETLS test. The Multivariate Analysis of the Variance was used to check the intergroup homogeneity of the sample in terms of general English proficiency. Finally, Independent-Sample T-Test was administered to check the difference between the means of the two treatment groups in the post-test. The statistical Analyses of this study were run via the Microsoft Windows-based Statistical Package for the Social Sciences (SPSS), version 22.0.

\section{Procedure and Results}

As the institute policy dictated, all learners had to take the institute placement test before registration in IELTS preparation classes and stage a performance of at least intermediate proficiency level. So the 66 members of the sample were all speakers of intermediate proficiency level or higher. However, the researchers still had to make sure the sample had an acceptable degree of homogeneity in terms of general English proficiency. To this end, a mock version of the IELTS test was administered. However, prior to the analysis of the test scores, the inter-rater reliability of the writing and speaking scores given by the two raters had to be checked. According to Table 2, the means of the raters in the speaking were 6.12 and 6.08, and in writing, the means were 5.62 and 5.73. Since all the 4 Skewness ratios fell well within the normal distribution range of \pm 1.96 , both distributions were distributed normally, and hence, Pearson Correlation was administered.

Table 2. Descriptive Statistics of the IELTS Pretest Speaking and Writing Scores Given by the Two Raters

\begin{tabular}{ccccc}
\hline & N & Mean & Std. Deviation & Skewness Ratio \\
\hline Speaking Rater 1 & 66 & 6.1288 & .92116 & -0.2983 \\
Speaking Rater 2 & 66 & 6.0833 & .78732 & 0.8542 \\
Writing Rater 1 & 66 & 5.6212 & .84608 & 0.06440 \\
Writing Rater 2 & 66 & 5.7348 & .70830 & -1.8847 \\
\hline
\end{tabular}

Table 3 depicts that the $p$ values for both correlations were $.000<0.05$, and the Pearson coefficients were .78 and .63 . Hence, both correlations were statistically significant, and both coefficients were larger than 0.5 . This proved that the inter-rater reliability of the scores is in an acceptable degree. Therefore, the researchers considered the average of the two raters' scores as the true score of each participant. 
Table 3. Pearson Correlation on the IELTS Pretest Speaking and Writing Scores Given by the Two Raters

\begin{tabular}{cccc}
\hline & & Rater 1 & Rater 2 \\
\hline \multirow{2}{*}{ Rater 1 } & Pearson Correlation & 1 & $.780^{* *}$ \\
& Sig. (2-tailed) & & .000 \\
Rater 2 & Pearson Correlation & $.780^{* * *}$ & 1 \\
& Sig. (2-tailed) & .000 & \\
\hline \multirow{2}{*}{ Rater 1 } & Pearson Correlation & 1 & $.638^{* *}$ \\
& Sig. (2-tailed) & & .000 \\
Rater 2 & Pearson Correlation & $.638^{* *}$ & 1 \\
& Sig. (2-tailed) & .000 & \\
\hline
\end{tabular}

As it could be witnessed in Table 4, the means of the sample in the skill of speaking is largest mean (6.1), whereas the reading mean (5.35) is the lowest. Writing and listening (5.67 and 5.38, respectively) were in the middle. In order to make sure that the participants in the two groups (consecutive narration and simultaneous narration) did not have any significant differences in their proficiency in any of these four skills, the researchers administered the Multivariate Analysis of the Variance.

Table 4. Descriptive Statistics of the IELTS Pretest Scores

\begin{tabular}{ccccc}
\hline & $\mathrm{N}$ & Mean & Std. Deviation & Skewness Ratio \\
\hline Speaking & 66 & 6.1061 & .80630 & 0.6305 \\
\hline Writing & 66 & 5.6780 & .70406 & -1.0780 \\
\hline Reading & 66 & 5.3561 & 1.17265 & 1.5390 \\
\hline Listening & 66 & 5.3864 & 1.19227 & 2.0610 \\
\hline
\end{tabular}

According to Table 5, all the four Multivariate tests reported the $p$ value of 0.599 at the 5\% level of significance; thus, MANOVA did not report any statistically significant differences among the means of the two treatment groups in the four skills, and it could hence be argued that the learners of the two groups enjoyed an almost equal level of proficiency in the four skills of reading, writing, listening and speaking.

Table 5. MANOVA on IELTS Pretest Scores

\begin{tabular}{cccccc}
\hline & Value & F & Hypothesis df & Error df & Sig. \\
\hline Pillai's trace & .044 & $.694^{\mathrm{a}}$ & 4.000 & 61.000 & .599 \\
Wilks' lambda & .956 & $.694^{\mathrm{a}}$ & 4.000 & 61.000 & .599 \\
Hotelling's trace & .045 & $.694^{\mathrm{a}}$ & 4.000 & 61.000 & .599 \\
Roy's largest root & .045 & $.694^{\mathrm{a}}$ & 4.000 & 61.000 & .599 \\
\hline
\end{tabular}

After the researchers made sure of the homogeneity of the sample in the four skills of reading, writing, listening and speaking, the administration of the treatment to the learners of the two group (in 6 classes) commenced. The quality, procedure and the materials of the treatments were discussed in section 2.3 above. One week after the completion of the treatment, the researchers administered the posttest IELTS speaking. Since the focus of the present study was on speaking skill, only the speaking section of the IELTS was administered in the posttest. Prior to the analysis of the scores, their inter-rater reliability had to be checked. The two sets of scores had the means of 7.01 and 6.97 , and Skewness ratios of -1.6 and 1.93 , both of which fell well within the normal distribution range of \pm 1.96 , both distributions were distributed normally; hence, Pearson Correlation was run. 
Table 6. Descriptive Statistics of the IELTS Posttest Speaking Scores Given by the Two Raters

\begin{tabular}{ccccc}
\hline & N & Mean & Std. Deviation & Skewness Ratio \\
\hline Speaking Rater 1 & 66 & 7.0152 & .71774 & -1.6034 \\
Speaking Rater 2 & 66 & 6.9773 & .64708 & -1.9390 \\
\hline
\end{tabular}

Based on Table 7, the Pearson Correlation analysis ( $p$ : $0.000<0.05$, coefficient: 0.854$)$ reported a significant correlation between the two sets of scores and the coefficient reported that the two sets of scores were positively correlated. This proved that the inter-rater reliability of the scores is in an acceptable degree. As a result, the researchers considered the average of the two raters' scores as the true score of each participant.

Table 7. Pearson Correlation on the IELTS Posttest Speaking Scores Given by the Two Raters

\begin{tabular}{cccc}
\hline & & Rater 1 & Rater 2 \\
\hline \multirow{2}{*}{ Rater 1 } & Pearson Correlation & 1 & $.854^{* *}$ \\
& Sig. (2-tailed) & & .000 \\
\multirow{2}{*}{ Rater 2 } & Pearson Correlation & $.854^{* *}$ & 1 \\
& Sig. (2-tailed) & .000 & \\
\hline
\end{tabular}

As Table 8 depicts, the overall mean of the sample in the posttest speaking was 6.99 , which showed 0.89 scores of improvement in comparison to the pretest speaking mean of 6.1. The Skewness ratio of the distribution was -1.91, which indicated that that the data had been distributed normally, and it was hence parametric.

Table 8. Descriptive Statistics of the IELTS Posttest Speaking Scores

\begin{tabular}{ccccc}
\hline & N & Mean & Std. Deviation & Skewness Ratio \\
\hline Speaking & 66 & 6.9962 & .65705 & -1.9153 \\
\hline
\end{tabular}

Table 9 demonstrates that the mean of the simultaneous narration group was 7.29, which stood 0.6 scores higher than the mean of the consecutive narration group (6.69). Since the data was parametric, the researchers administered the parametric test of Independent-Sample T-Test to determine whether or not the differences between the two means were significant.

Table 9. Descriptive Statistics of the IELTS Posttest Speaking Scores in the Consecutive Narration and Simultaneous Narration Groups

\begin{tabular}{lccc}
\hline & $\mathrm{N}$ & Mean & Std. Deviation \\
\hline Simultaneous Narration Group & 33 & 7.2955 & .62329 \\
\hline Consecutive Narration Group & 33 & 6.6970 & .55113 \\
\hline
\end{tabular}

As the results of the Independent-Sample T-Test, illustrated in Table 10, highlight, Levene's Test for Equality of Variances $(p: 0.916>0.05, F: 0.11)$ reported that the variances were not equal. Hence, the results for the second row (equal variances not assumed) must be reported. The T-Test results $(p: 0.000<0.05$, $d f: 63.053$, and $t: 4.132)$ highlighted that the difference between the means of the two groups was statistically significant. Hence, the research hypothesis of this study was rejected, and the data analysis confirmed that simultaneous narration treatment (owing to the larger mean in the posttest) was a more effective technique than consecutive narration in developing the oral communication skills of EFL learners. 
Table 10. Independent-Sample T-Test on IELTS Posttest Speaking Scores of the Consecutive Narration and Simultaneous Narration Groups

\begin{tabular}{|c|c|c|c|c|c|c|c|c|c|}
\hline & \multicolumn{2}{|c|}{ Levene's Test } & \multicolumn{7}{|c|}{ t-test for Equality of Means } \\
\hline & \multirow[t]{2}{*}{$\mathrm{F}$} & \multirow[t]{2}{*}{ Sig. } & \multirow[t]{2}{*}{$\mathrm{t}$} & \multirow[t]{2}{*}{$\mathrm{df}$} & \multirow{2}{*}{$\begin{array}{c}\text { Sig. } \\
\text { (2-taile } \\
\text { d) }\end{array}$} & \multirow{2}{*}{$\begin{array}{c}\text { Mean } \\
\text { Difference }\end{array}$} & \multirow{2}{*}{$\begin{array}{l}\text { Std. Error } \\
\text { Difference }\end{array}$} & \multicolumn{2}{|c|}{$\begin{array}{c}95 \% \text { Confidence Interval } \\
\text { of the Difference }\end{array}$} \\
\hline & & & & & & & & Lower & Upper \\
\hline $\begin{array}{c}\text { Equal } \\
\text { variances }\end{array}$ & .011 & .916 & 4.132 & 64 & .000 & .59848 & .14483 & .30915 & .88782 \\
\hline assumed & & & & & & & & & \\
\hline Equal & & & & & & & & & \\
\hline variances not & & & 4.132 & 63.055 & .000 & .59848 & .14483 & .30906 & .88791 \\
\hline assumed & & & & & & & & & \\
\hline
\end{tabular}

\section{Discussion}

The findings of this study highlighted that simultaneous narration is a more effective technique in promoting learners' oral communication skills compared to consecutive narration. A variety of reasons could be offered for this trend. First, Rivers (1968) believed that learners' awareness and topical knowledge of what is being talked about in the class is the key to improve their L2 speaking skills, since if they have nothing to say, they do not speak frequently, do not get enough practice, and hence their speaking does not improve. In this study, learners always have the content material in their mind since the topic of speaking was the actions in the videos to which they were constantly exposed. It could therefore be argued that simultaneous narration provided learners with ample practice material and frequent exposure caused them to always have something to say.

In terms of SLA, Van Patten and Benati (2015) pointed out the following criteria from which analysis of the study aligned. Firstly, the role of enriched input is important; simultaneous narration as compared to consecutive narration has more potentiality and availability to be enriched since it is proactive and online narration than be retrospective and offline one. Secondly, Input Processing (IP) focuses on the order of linguistics element from Content Word Preference Principle to Sentence Location Preference Principle; acquisition is a by-product of comprehension during which form-meaning connection is made; simultaneous task extracts more exposure to connect form to meaning before input becomes intake in comprehension process. Thirdly, Processing Theory (PT) focuses on morphological sequence and stage of development in such a way that without considering sequence and stage, no acquisition will be completed, in other words, the final stage and sequence of acquiring a linguistic elements cannot be attained unless the very early stage and sequences are acquired; simultaneous narration has more monotonous image including topic and the context beyond that to follow sequence, stage , and even variability as compared to consecutive narration. Additionally, planned Form-Function Instruction (consecutive narration) as compared to unplanned Form-Function Instruction (simultaneous narration) is task-supported procedure than task-based procedure which needs 3Ps(Presentation, Practice, Production) where task -based engages learners with real communication interaction or authentic language use.

Moreover, MacIntyre (2007) proposed willingness to communicate as a significant factor that promotes learners' oral communication skills. Better put, the more willing the learners are to voluntarily communicate, the more chances arise for them to practice production in L2 and the higher their rate of learning communication skills will be. While doing simultaneous narration, learners had to push themselves to keep up with the pace of the video and try hard to speak as fast as possible not to fall behind. Hence, simultaneous narration provided them with abundant motivation to talk and strikingly increased their willingness to communicate. In addition, Hatch (1978) emphasized that L2 learners require a broad range of topics to talk about and experience various genres. Simultaneous narration, naturally, could be applied on all types of motion pictures, and as illustrated in Table 1, extracts used in this study were chosen from different genres of movies. Accordingly, simultaneous narration in this study gave learners a broad scope of topics to talk about.

Macaro (2001) stressed that in conversational interactions, a large number of language deficiencies could be compensated by body language, gestures, mimics, guessing and the like. Admittedly, by using speaking strategies, learners could compensate their weaknesses in verbal communication. However, while narrating the actions and 
scenes of the view simultaneously, learners could only use pure verbal skills in order to narrate the scenes and actions in the movie. Hence, the practice that they did was purely verbal. Not having a chance to use compensation strategies, learners had to rely on their verbal skills merely, and the concentrated practice improved their oral skills.

Finally, Littlewood (2007) believed that inhibition was one of the key reasons why learners fell behind in developing L2 oral production skills. In this study, however, no inhibition was observed in the learners while they were narrating the movie scenes, since it turned to a routine procedure for them after several times of practice. Also, having to keep up with the pace of the movie was an excellent inhibition breaker. Additionally, narration facilitated the maximum student talk time in the class, which according to Paul (2003), plays a key role in enhancing learners' oral skills.

\section{Conclusion}

In conclusion, this study set out to investigate the comparative impacts of simultaneous narration and consecutive narration on the enhancement of EFL learners' oral communication skills. Unlike Cohen and Olshtain (1993), who proposed that encouraging retrospective think-aloud protocols (i.e., assessing, planning, and executing) and accelerating this process would help improve the production of learners, this study used narration technique which was a think-aloud version of learners' reception and processing of videos. Two groups of 33 IELTS Speaking preparation class learners were selected, their inter-group homogeneity in terms of listening, reading, writing and speaking skills were checked, and the treatments of simultaneous narration and consecutive narration were administered to them.

The statistical analysis of the posttest results indicated that learners who narrated the actions in movie extracts simultaneously as they watched them staged a greater amount of improvement in their speaking skill compared to those who watch the movie extracts first and narrated their plot later. This finding indicates that simultaneous narration, as simple and uncomplicated and easy-to-practice as it is, could be an adequate and operational technique to be used in English classes (and in L2 classes in a more general level) to boost the speaking skills of all learners. Having content material to talk about, receiving maximal willingness to communication, not being able to use compensation strategies, having a wide range of topic to talk about, decreased sense of inhibition and the maximum student talk time were the main reasons why simultaneous narration was effective in fostering L2 oral communication skills of the learners.

\section{Implications}

The findings of this study bear a large number of pedagogical implications. Since this study proved the effectiveness of a classroom procedure practice that could promote the oral communication skills of the learners in L2, it has implications for all English teachers, particularly those with learners in dire need or fostering their speaking skills. Besides, the findings have implications for all teacher trainers in the field of L2 pedagogy, which could be incorporated in their syllabi for training rookie teachers in teacher education programs and updating professional teachers' teaching speaking skills in on-the-job training workshops. Teachers who teach international exam preparation classes could also utilize the findings of this study to prepare the candidates for the speaking sections of these tests (e.g. IELTS and iBT TOEFL).

Since the technique that proved to be effective in fostering L2 learners' speaking proficiency involved only watching a movie extract and simultaneous narration, this technique is an appropriate technique for learners who would like to self-study and are seeking a means to promote their speaking skills. Moreover, trainers of simultaneous interpreters who need to make sure their learners pick up advanced oral communication skills could also gain benefits from the findings of this study. Finally, another group for whom the findings of this study provides implications are material developers who develop books and multimedia for promoting speaking skills of the learners. In the light of the results this study yielded, it would be a good idea for them to include some movie extracts in their materials to give learners a chance to do simultaneous narration on them.

\section{Suggestions}

The researchers would like to propose the following points as suggestions for further investigation:

- Investigating the comparative impacts of simultaneous narration and consecutive narration on learners of other age groups (e.g. young learners and teenagers)

- Probing the effectiveness of simultaneous narration on the sub-component of speaking skill (fluency, accuracy, listeners' effort, pronunciation, and complexity)

- Comparing the effects of simultaneous narration and consecutive narration on fostering oral communication skills of learners with various intelligences (visual, verbal, auditory, and the like), and various personality 
variable and personal skills

- Determining whether or not simultaneous narration is a technique that could promote the autonomy of the learners

- Investigating if simultaneous narration could be effective in developing the speaking of learners of other proficiency levels

- Finding out whether or not simultaneous narration and consecutive narration could be effective in promoting the oral skills and sociability of apprehensive and shy learners

\section{References}

Bachman, L., \& Palmer, A. S. (1996). Language Testing in Practice. Oxford: Oxford University Press.

Bailey, K. M. (2005). Practical English language teaching: Speaking. New York: McGraw-Hill. Faculty of Arts, (2004). Undergraduate catalog. Nakhon Pathom, Thailand: Silpakorn University Press.

Bailey, K. M., \& Savage, L. (1994). New ways in teaching speaking. TESOL Quarterly, 22, 6 -7.

Baker, J., \& Westrup. H. (2003). Essential speaking skills: A handbook for English language teachers. London: Continuun International Publishing.

Brown, G., \& Yule, G. (1983). Teaching the spoken language. Cambridge: Cambridge University Press.

Bygate, M. (1987). Speaking. Oxford: Oxford University Press.

Cambridge Local Examinations Syndicate (2015). Cambridge United Kingdom: Cambridge University Press.

Cohen, A. D. (1998). Strategies in learning and using a second language. Essex, U.K.: Longman.

Cohen, A. D., \& Olshtain, E. (1993). The production of speech acts by EFL learners. TESOL Quarterly, 27(1), 33-56.

Davies, P., \& Pearse, E. (2000). Success in English teaching. Oxford University Press.

Doff, A. (1998). Teach English: A training course for teacher. Cambridge University Press.

Ducate, L., \& Lomicka, L. (2009). Podcasting: An effective tool for honing language students' pronunciation? Language Learning \& Technology, 13(3), 66-86.

Hatch, E. (1978). Discourse analysis and second language acquisition. In: HATCH, E. (Ed.), Second language acquisition. Rowley, MA: Newbury House.

Johnson, D. W., \& Johnson, R. T. (1998). Learning together and alone: Cooperative, competitive, and individualistic learning (5th ed.), Boston: Allyn \& Bacon.

Khan, B. H. (2005). Managing e-learning: Design, delivery, implementation, and evaluation. Hershey, PA: Information Science Publishing. Retrieved on 6th January from http://BooksToRead.com/elearning.

Krashen, S. D. (1982). Principles and practice in second language acquisition. New York: Pergamon Press.

Littlewood, W. (2007). Communicative language teaching. Cambridge: Cambridge University Press.

Macaro, E. (2001). Analyzing student teachers' code switching in foreign language classrooms: Theories and decision making. The Modern Language Journal, 85(4), 531-548.

MacIntyre, P. D. (2007). Willingness to communicate in the second language: Understanding the decision to speak as a volitional process. The Modern Language Journal, 91, 564-576.

Nunan, D. (1998). Approaches to teaching listening in the language classroom. Paper presented at the Korea TESOL Conference, Seoul.

Nunan, D. (1999). Second language teaching and learning. Heinle and Heinle.

Paul, D. (2003). Teaching English to children in Asia. Asia: Longman.

Richards, J. C. (2006). Developing classroom speaking activities: From theory to practice. Guidelines. RELC, Singapore, 28, 3-9. 
Richards, J., Platt, J., \& Weber, H. (1985). Longman dictionary of applied linguistics. London: Longman.

Rivers, W. (1968). Teaching Foreign Language Skills. Chicago: University of Chicago Press.

Songsiri, M. (2007). An action research study of promoting students' confidence in speaking English. (Dissertation of Doctor of Education Degree), School of Arts, Education and Human Development, Victoria University, Australia. Retrieved from: eprints.vu.edu.au/1492/1/Songsiri.pdf

Tam, M. (1997). Building fluency: a course for non-native speakers of English. English Teaching Forum, 35(1), 26. Retrieved from http://eca.state.gov/forum/vols/vol35/no1/p26.htm.

Thurlow, S., \& O'Sullivan, K. (2011). Focusing on IELTS - Listening and Speaking Skill. Australia: Macmillan Education.

Van Patten, B., \& Benati, A. (2015). Key Terms in Second Language Acquisition. Second Ed. London: Bloomsbury Academic Publication. 